\title{
Bacillaenes: Decomposition Trigger Point and Biofilm Enhancement in Bacillus
}

\author{
Huayue Li, Xiao Han, Yujing Dong, Shanshan Xu, Chao Chen, Yingang Feng, Qiu Cui, and Wenli Li*
}

Cite This: ACS Omega 2021, 6, 1093-1098

Read Online

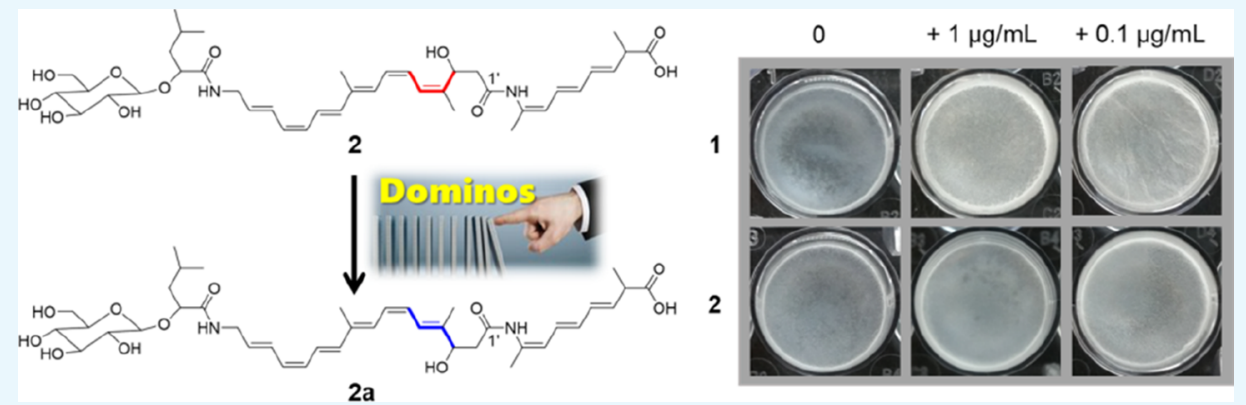

ABSTRACT: Bacillaenes are a class of poly-unsaturated enamines produced by Bacillus strains that are notoriously unstable toward light, oxygen, and normal temperature. Herein, in an in-depth study of this highly unstable chemotype, the stability and biological function of bacillaenes were investigated. The structure change of the bacillaene scaffold was tracked by time-course ${ }^{1} \mathrm{H}$ NMR data analysis coupled with the differential analysis of 2D-NMR spectra method, which was demonstrated to be a "domino" effect triggered by $4^{\prime}, 5^{\prime}$-cis ( 2 and 3 ) configuration rearranged to trans ( $2 a$ and $\left.3 a\right)$. These findings provide the possibility for stabilizing the bacillaene scaffold by chemical modification of its trigger points. In the biofilm assay, compounds 1 and 2 accelerated self-biofilm formation in Bacillus methylotrophicus B-9987 at low concentrations of 1.0 and $0.1 \mu \mathrm{g} / \mathrm{mL}$. Interestingly, bacillaenes play dual roles as antibiotic and biofilm enhancers in a dose-dependent manner, both of which serve in the self-protection of Bacillus.

\section{INTRODUCTION}

Unstable secondary metabolites are a rarely explored area of natural product research. Bacillaenes are a class of polyunsaturated enamines encoded by a trans-acyltransferase polyketide synthetase machinery in a wide range of Bacillus strains that are notoriously unstable toward light, oxygen, and normal temperature. ${ }^{1-4}$ Since the first discovery in $1995,{ }^{1}$ their structures have not been identified for a decade because of chemical instability, until the arduous task was completed by Clardy and Walsh groups in 2007. ${ }^{2}$ According to the literature studies, bacillaenes are considered as antibiotic weapons for Bacillus to resist other environmental microbes. ${ }^{1,5-7}$ However, from the perspective of evolution, it does not seem to be enough because the bacillaene-producing Bacillus strains encode a variety of structurally stable antibiotics. ${ }^{8-11}$

In our recent study on bacillaenes, we identified a series of new glycosylated bacillaenes (gBAEs) $\left(14^{\prime}, 15^{\prime}\right.$-dihydro-bacillaene B, 12',13'-trans-14',15'-dihydro-bacillaene $B$, and bacillaene C) using a combined strategy of genome, 2DNMR metabolome coupled with bioassay, and illustrated that glycosylation generally decreases the antibacterial activity. ${ }^{12}$ Herein, as continuing studies, the stability and biological function of bacillaenes were investigated. The degradation trigger point of the bacillaene scaffold was caught and determined by time-course ${ }^{1} \mathrm{H}$ NMR data analysis coupled with DANS (differential analysis of 2D-NMR spectra) method; moreover, the effect of bacillaenes on the biofilm formation of Bacillus strains was probed in a dose-dependent manner.

\section{RESULTS AND DISCUSSION}

Because of the unstable bacillaene chemotype, the structural stability throughout the biological evaluation is one of the most concerning issues. Pure 1-3, which are the major bacillaene compounds, were prepared from the fermentation culture of the $\Delta b m m B$ mutant strain of Bacillus methylotrophicus B-9987. The molecular formulas of 1-3 were established as $\mathrm{C}_{34} \mathrm{H}_{48} \mathrm{~N}_{2} \mathrm{O}_{6}, \mathrm{C}_{40} \mathrm{H}_{58} \mathrm{~N}_{2} \mathrm{O}_{11}$, and $\mathrm{C}_{40} \mathrm{H}_{60} \mathrm{~N}_{2} \mathrm{O}_{11}$, respectively, on the basis of the HR-ESIMS data $\left([\mathrm{M}+\mathrm{H}]^{+}\right.$at $\mathrm{m} / \mathrm{z}$ $581.3595,743.4163$, and 745.4280). Compounds 1 and 3 were confirmed to be bacillaene A and $14^{\prime}, 15^{\prime}$-dihydro-bacillaene B, respectively, as reported in our earlier work, ${ }^{12}$ and 2 was identified as bacillaene $\mathrm{B}^{13}$ by $1 \mathrm{D}$ and $2 \mathrm{D}$ NMR data

Received: July 15, 2020

Accepted: October 19, 2020

Published: January 8, 2021 

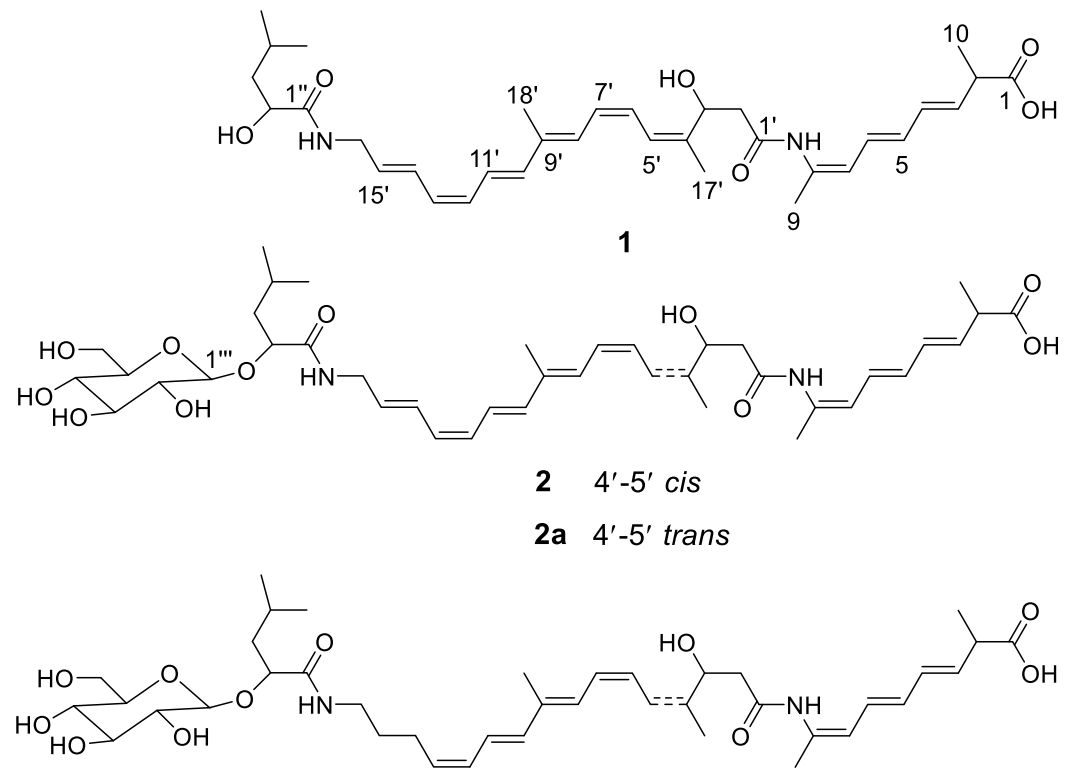

$3 \quad 4^{\prime}-5^{\prime}$ cis

3a $4^{\prime}-5^{\prime}$ trans

assignments (Figure S7 and Table S1). Compounds 1 and 2, being quantified by the standard curves, underwent time- (0$48 \mathrm{~h})$ and dose-dependent $(0.1-10 \mu \mathrm{g} / \mathrm{mL})$ stability tests at normal bioassay conditions (aqueous solution system, $37{ }^{\circ} \mathrm{C}$, in the dark) using UPLC-MS. As shown in Figure S8, bacillaene A (1) was rather unstable in aqueous solution. Bacillaene B (2), a 2"-O-glycosylated bacillaene A analogue, kept stable up to $10 \mu \mathrm{g} / \mathrm{mL}$ within $18 \mathrm{~h}$, and in a longer period, its stability might be concentration-dependent. Decomposition of the non-gBAEs was more easily triggered compared to the glycosylated analogues. This result revealed that the glycosylation stabilizes the bacillaene scaffold, which supports our previous suggestion. ${ }^{12}$

To understand the decomposition mode of the bacillaene scaffold, we used the time-course ${ }^{1} \mathrm{H}$ NMR data collection method to capture the structural changes of the compounds. We prepared the pure sample (PS) and the decompositiontriggered sample (DTS) of compound 3 as described in the Experimental Section. Except for the light, the decomposition of 3 mostly occurred when the compound dose was over a threshold and exposed to oxygen, starting the initial conversion to a stereoisomer 3a (Figure 1A,B). Compound 3a was the first "shapeshift" of $\mathbf{3}$ once the degradation was triggered. According to the time-course ${ }^{1} \mathrm{H}$ NMR data, PS-3 was stable up to $68 \mathrm{~h}$ at $274 \mathrm{~K}$ (Figure S9); however, compound 3 in DTS-3 was rapidly converted to $3 \mathrm{a}$, which was determined by the signal decrease of $\mathrm{H}-2^{\prime}\left(\delta_{\mathrm{H}} 2.70,2.45\right)$ and $\mathrm{H}-5^{\prime}\left(\delta_{\mathrm{H}} 6.55\right)$ in the $0 \mathrm{~h}^{1} \mathrm{H}$ NMR spectrum of DTS-3 (Figure $1 \mathrm{C}$ ). Moreover, the time-dependent $(0-18 \mathrm{~h})$ signal decrease of $\mathrm{H}$ $10\left(\delta_{\mathrm{H}} 1.23\right)$ and $\mathrm{H}-3^{\prime}\left(\delta_{\mathrm{H}} 4.54\right)$ in the ${ }^{1} \mathrm{H}$ NMR of DTS-3 suggested that $3 \mathrm{a}$ continuously changed even at $274 \mathrm{~K}$ (Figure 1C). To determine the structure of $3 a$, the Heteronuclear Single Quantum Coherence (HSQC), DQF-COSY, Heteronuclear Multiple Bond Coherence (HMBC), and NOESY data of DTS-3 were sequentially collected. In the differential analysis of the HSQC spectra of PS-3 and DTS-3, the protonated carbons of $2^{\prime}, 3^{\prime}, 5^{\prime}-8^{\prime}$, and $17^{\prime}$ showed wide chemical shift differences between 3 and $3 a$, while other signals almost kept identical (Figure 1D). It strongly suggested that a structural change occurred in this part. However, because of the continuous changes of $3 a$ during the $2 \mathrm{D}$ NMR data collection, the key HMBC correlations could not be fully observed. Considering that C- $4^{\prime}$ and $\mathrm{C}-5^{\prime}$ are the "centers" of the NMR shift changes, $3 \mathbf{a}$ was proposed to be the $4^{\prime}, 5^{\prime}$-trans stereoisomer of 3 , and it was supported by the ${ }^{13} \mathrm{C}$ chemical shift prediction of 3/3a in ChemBioDraw 15.0 (Figure S12).

To further confirm the trigger point of structure changes in other bacillaenes, we prepared PS-2 and DTS- 2 to conduct the time-course ${ }^{1} \mathrm{H}$ NMR experiments. PS-2 was stable up to $84 \mathrm{~h}$ (Figure S13), whereas a large part of compound 2 in DTS-2 had been converted to $\mathbf{2 a}$ at the beginning of the NMR data collection (Figure S14). In order to obtain key HMBC correlations to assign the structure of $\mathbf{2 a}$, the freshly prepared DTS-2 was first conducted to the HMBC data collection, and then the HSQC and the DQF-COSY data were sequentially obtained. According to the differential analysis of the HSQC spectra of PS-2 and DTS-2 (Figure S16), the peaks of 2', 3', $5^{\prime}-8^{\prime}$, and $17^{\prime}$ of 2 underwent large chemical shifts when converting to 2a. These NMR shift changes were in accordance with those between 3 and $3 a$ (Figure 1D). In the HMBC spectrum of DTS-2 (Figure S17), we observed the correlations from $\mathrm{H}-3^{\prime}\left(\delta_{\mathrm{H}} 4.54\right)$ to C-1' $\left(\delta_{\mathrm{C}} 170.7\right), \mathrm{C}-2^{\prime}\left(\delta_{\mathrm{C}}\right.$ $42.1), \mathrm{C}-4^{\prime}\left(\delta_{\mathrm{C}} 139.2\right), \mathrm{C}-5^{\prime}\left(\delta_{\mathrm{C}} 126.5\right)$, and C-17' $\left(\delta_{\mathrm{C}} 11.1\right)$, which undoubtedly determined the location of the structural changes. The experimental NMR data of $\mathbf{2 a}$ (Table 1) were supported by the ${ }^{13} \mathrm{C}$ chemical shift prediction of $4^{\prime}, 5^{\prime}$-trans stereoisomer of 2 calculated by ChemBioDraw 15.0 (Figure S18). Thus, we proposed that the bacillaene scaffold is "dominos" triggered by $4^{\prime}, 5^{\prime}$-cis configuration rearranged to trans. These findings provide the possibility for stabilizing the bacillaene scaffold by chemical modification of its trigger points.

Kolter et al. reported in their recent review that many of the antibiotic secondary metabolites might have different functions (e.g. virulence, colonization, motility, stress response, and/or biofilm formation) in nature at their subinhibitory concentrations (SICs). ${ }^{14}$ Interestingly, we observed that both of bacillaene A (1) and bacillaene B (2) accelerated self-biofilm 
(A)

(B) LC-MS TIC
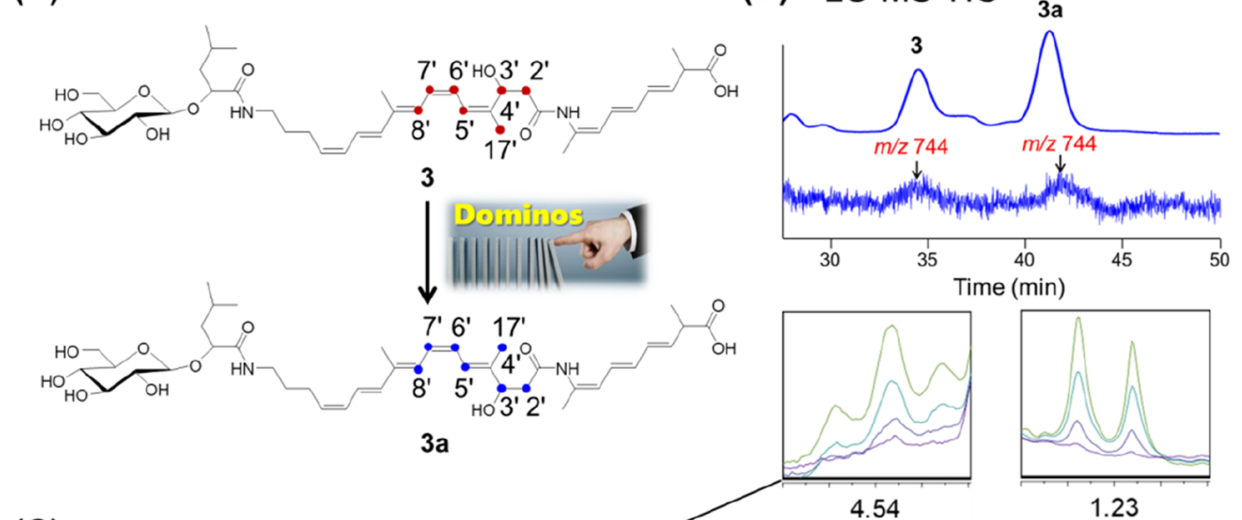

(C) ${ }^{1} \mathrm{H}$ NMR
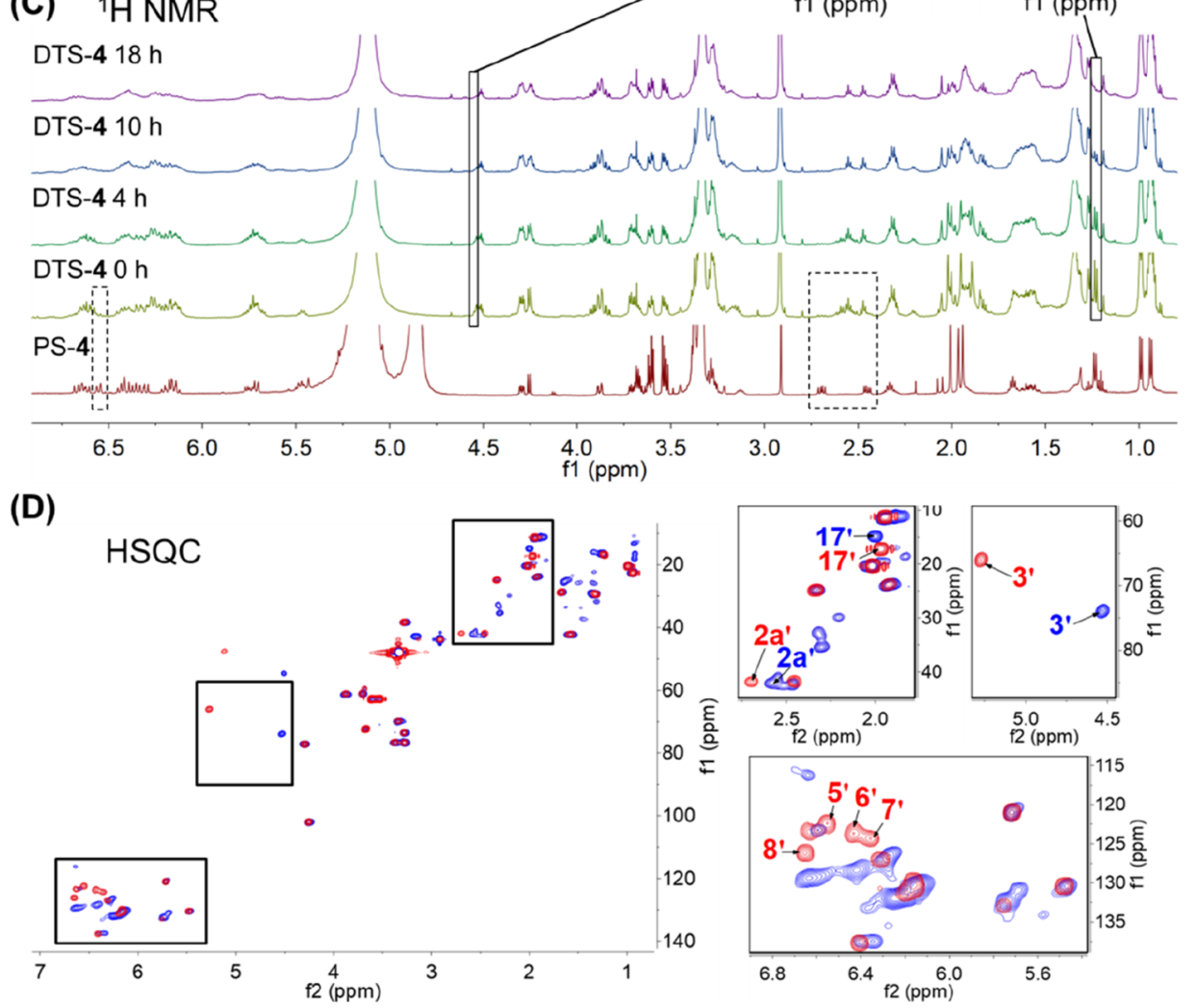

Figure 1. Determination of the decomposition trigger point of the bacillaene scaffold. (A) Structures of 3 and its stereoisomer 3a. (B) LC-MS TIC data of the DTS of 3 (DTS-3). (C) Time-course $(0,4,10$, and $18 \mathrm{~h}){ }^{1} \mathrm{H}$ NMR spectra of DTS-3 and ${ }^{1} \mathrm{H}$ NMR spectrum of PS-3 (in CD $\mathrm{OD}$, $600 \mathrm{MHz}$ at $274 \mathrm{~K})$. In DTS-3, majority of compound 3 had been converted to the stereoisomer $3 \mathrm{a}$ and other unknown compounds at the start $(0$ h) of NMR data collection, which was determined by significant signal decrease of $\delta_{\mathrm{H}} 6.55\left(\mathrm{H}-5^{\prime}\right)$ and $\delta_{\mathrm{H}} 2.70,2.45\left(\mathrm{H}_{2}-2^{\prime}\right)$. The continuous signal decrease of $\delta_{\mathrm{H}} 1.23(\mathrm{H}-10)$ and $\delta_{\mathrm{H}} 4.53\left(\mathrm{H}-3^{\prime}\right)$ revealed that $3 \mathrm{a}$ continuously changed with the increasing time. (D) Differential HSQC analysis of PS-3 (red) and DTS-3 (blue). The carbons of $2^{\prime}, 3^{\prime}, 5^{\prime}-8^{\prime}$, and $17^{\prime}$ showing wide chemical shift differences between 3 and $3 a$ are labeled in red and blue, respectively. The bacillaene scaffold was determined to be "dominos" triggered by the $4^{\prime}, 5^{\prime}$-cis configuration rearranged to trans.

formation in the B-9987 strain at low concentrations of 1.0 and $0.1 \mu \mathrm{g} / \mathrm{mL}$ (Figure 2), which were far below than their antibiotic MICs $(>10 \mu \mathrm{g} / \mathrm{mL}) .{ }^{12,15}$ Then, to further evaluate the effects of bacillaenes on the self-biofilm formation in the B9987 strain at higher concentrations, we used Fr. BAEs/Fr. gBAEs, which were more stable than pure compounds (Figure S19), to conduct the experiments. The Fr. BAEs enhanced the biofilm formation in B-9987 at the concentration of $0.01 \mu \mathrm{g} /$ $\mathrm{mL}$ within $24 \mathrm{~h}$ of incubation, whereas at $100 \mu \mathrm{g} / \mathrm{mL}$, it completely inhibited the B-9987 growth (Figure S20A). Then, the bacterial growth began to recover from $36 \mathrm{~h}$ of incubation (Figure S20A), at which timepoint Fr. BAEs had been extensively degraded (Figure S19). In the concentration range of $0.1-10 \mu \mathrm{g} / \mathrm{mL}$, the Fr. BAEs demonstrated neither biofilm enhancement nor the growth inhibition in B-9987 (Figure S20A). Fr. gBAEs enhanced the biofilm formation in B-9987 at $0.01 \mu \mathrm{g} / \mathrm{mL}$ as well but did not show notable toxicity toward the cells up to $100 \mu \mathrm{g} / \mathrm{mL}$ (Figure S20B), indicating that the glycosylation has a detoxication effect on the host strain. Similar phenomena were observed when the bacillaene fractions were treated to another bacillaeneproducing Bacillus sp. 5746 strain (Figure S21).

Upon these results, we deduced that through long time evolution, the Bacillus strains might encode bacillaenes as important signal molecules contributing to self-biofilm formation at low SICs. Then, at inhibitory concentrations, 
Table $1 .{ }^{1} \mathrm{H}$ and ${ }^{13} \mathrm{C}$ Chemical Shifts of Compounds $2 \mathrm{a}$ and 3a Obtained from the NMR Spectra of DTS-2 and DTS-3, Respectively (in $\mathrm{CD}_{3} \mathrm{OD}, 600 \mathrm{MHz}$ )

\begin{tabular}{|c|c|c|c|c|}
\hline \multirow[b]{2}{*}{ position } & \multicolumn{2}{|c|}{$2 a$} & \multicolumn{2}{|r|}{$3 a$} \\
\hline & $\delta_{\mathrm{C}}$, type & $\delta_{\mathrm{H}}(J$ in $\mathrm{Hz})$ & $\delta_{\mathrm{C}}$, type & $\delta_{\mathrm{H}}(\mathrm{J}$ in $\mathrm{Hz})$ \\
\hline 1 & 177.3, C & & 177.0, C & \\
\hline 2 & $42.9, \mathrm{CH}$ & $3.15, \mathrm{~m}$ & $42.9, \mathrm{CH}$ & $3.17, \mathrm{~m}$ \\
\hline 3 & 132.2, $\mathrm{CH}$ & $5.72, \mathrm{~m}$ & $130.9, \mathrm{CH}$ & $5.68, \mathrm{~m}$ \\
\hline 4 & 131.9, CH & $6.18, \mathrm{~m}$ & $a$ & $a$ \\
\hline 5 & $a$ & $a$ & $a$ & $a$ \\
\hline 6 & 126.6, CH & $6.29, \mathrm{~m}$ & $a$ & $a$ \\
\hline 7 & 121.4, CH & $5.74, \mathrm{~m}$ & 121.0, $\mathrm{CH}$ & $5.72, \mathrm{~m}$ \\
\hline 8 & 132.1, C & & 132.3, C & \\
\hline 9 & 20.4, $\mathrm{CH}_{3}$ & $2.00, \mathrm{~s}$ & 20.4, $\mathrm{CH}_{3}$ & $2.02, \mathrm{~s}$ \\
\hline 10 & $16.5, \mathrm{CH}_{3}$ & $1.23, \mathrm{~d}, 7.2$ & 16.9, $\mathrm{CH}_{3}$ & $1.23, \mathrm{~d}, 6.6$ \\
\hline $1^{\prime}$ & $170.7, \mathrm{C}$ & & $a$ & \\
\hline $2^{\prime}$ & 42.1, $\mathrm{CH}_{2}$ & $2.60, \mathrm{~m}$ & 42.1, $\mathrm{CH}_{2}$ & 2.57 \\
\hline $3^{\prime}$ & $74.0, \mathrm{CH}$ & $4.54, \mathrm{t}(6.6)$ & $73.9, \mathrm{CH}$ & $4.53, \mathrm{t}(7.2)$ \\
\hline $4^{\prime}$ & 139.2, C & & 139.3, C & \\
\hline $5^{\prime}$ & 126.5, CH & $6.28, \mathrm{~m}$ & 126.7, CH & $6.27, \mathrm{~m}$ \\
\hline $6^{\prime}$ & 129.4, CH & $6.64, \mathrm{~m}$ & $a$ & $a$ \\
\hline $7^{\prime}$ & 130.1, CH & $6.28, \mathrm{~m}$ & $a$ & $a$ \\
\hline $8^{\prime}$ & 132.9, CH & $6.33, \mathrm{~m}$ & $131.9, \mathrm{CH}$ & $6.24, \mathrm{~m}$ \\
\hline $9^{\prime}$ & $135.4, \mathrm{C}$ & & 135.4, C & \\
\hline $10^{\prime}$ & 138.0, CH & $6.39, \mathrm{~m}$ & $137.5, \mathrm{CH}$ & $6.34, \mathrm{~m}$ \\
\hline $11^{\prime}$ & 123.2, $\mathrm{CH}$ & $6.79, \mathrm{~m}$ & $128.7, \mathrm{CH}$ & $6.34, \mathrm{~m}$ \\
\hline $12^{\prime}$ & 129.9, CH & $6.10, \mathrm{~m}$ & 131.8, $\mathrm{CH}$ & $6.23, \mathrm{~m}$ \\
\hline $13^{\prime}$ & 127.9, $\mathrm{CH}$ & $6.02, \mathrm{~m}$ & 133.3, $\mathrm{CH}$ & $5.78, \mathrm{~m}$ \\
\hline $14^{\prime}$ & 127.2, $\mathrm{CH}$ & $6.78, \mathrm{~m}$ & 29.9, $\mathrm{CH}_{2}$ & $2.21, \mathrm{~m}$ \\
\hline $15^{\prime}$ & 129.1, CH & $5.75, \mathrm{~m}$ & 28.5, $\mathrm{CH}_{2}$ & 1.67, m \\
\hline $16^{\prime}$ & $38.3, \mathrm{CH}_{2}$ & $\begin{array}{l}4.05, \mathrm{~m} \\
3.91, \mathrm{~m}\end{array}$ & 38.3, $\mathrm{CH}_{2}$ & $3.27, \mathrm{~m}$ \\
\hline $17^{\prime}$ & 17.2, $\mathrm{CH}_{3}$ & $1.97, \mathrm{~s}$ & 17.2, $\mathrm{CH}_{3}$ & $1.96, \mathrm{~s}$ \\
\hline $18^{\prime}$ & 11.3, $\mathrm{CH}_{3}$ & $1.94, \mathrm{~s}$ & $11.1, \mathrm{CH}_{3}$ & $1.90, \mathrm{~s}$ \\
\hline $1^{\prime \prime}$ & $174.2, \mathrm{C}$ & & $174.4, \mathrm{C}$ & \\
\hline $2^{\prime \prime}$ & 77.1, $\mathrm{CH}$ & $4.35, \mathrm{~m}$ & $77.2, \mathrm{CH}$ & 4.30 , dd $(9.0,3.6)$ \\
\hline $3^{\prime \prime}$ & 42.3, $\mathrm{CH}_{2}$ & $\begin{array}{l}1.65, \mathrm{~m} \\
1.57, \mathrm{~m}\end{array}$ & 42.2, $\mathrm{CH}_{2}$ & $\begin{array}{l}1.62, \mathrm{~m} \\
1.57, \mathrm{~m}\end{array}$ \\
\hline $4^{\prime \prime}$ & 23.8, $\mathrm{CH}$ & $1.92, \mathrm{~m}$ & 23.7, $\mathrm{CH}$ & $1.92, \mathrm{~m}$ \\
\hline $5^{\prime \prime}$ & 20.6, $\mathrm{CH}_{3}$ & $1.00, \mathrm{~d}(6.6)$ & 20.5, $\mathrm{CH}_{3}$ & $1.00, \mathrm{~d}(6.6)$ \\
\hline $6^{\prime \prime}$ & 22.5, $\mathrm{CH}_{3}$ & $0.95, \mathrm{~d}(6.6)$ & 22.5, $\mathrm{CH}_{3}$ & $0.95, \mathrm{~d}(6.6)$ \\
\hline $1^{\prime \prime \prime}$ & 101.9, CH & $4.27, \mathrm{~d}(7.8)$ & 102.1, $\mathrm{CH}$ & $4.25, \mathrm{~d}(7.8)$ \\
\hline $2^{\prime \prime \prime}$ & 73.5, $\mathrm{CH}$ & $3.29, \mathrm{~m}$ & 73.6, $\mathrm{CH}$ & $3.29, \mathrm{~m}$ \\
\hline $3^{\prime \prime \prime}$ & $76.4, \mathrm{CH}$ & $3.40, \mathrm{~m}$ & 76.6, $\mathrm{CH}$ & $3.38, \mathrm{~m}$ \\
\hline $4^{\prime \prime \prime}$ & 69.7, $\mathrm{CH}$ & $3.33, \mathrm{~m}$ & 69.9, $\mathrm{CH}$ & $3.34, \mathrm{~m}$ \\
\hline $5^{\prime \prime \prime}$ & 76.5, $\mathrm{CH}$ & $3.30, \mathrm{~m}$ & 76.7, $\mathrm{CH}$ & $3.28, \mathrm{~m}$ \\
\hline $6^{\prime \prime \prime}$ & 61.0, $\mathrm{CH}_{2}$ & $\begin{array}{l}3.88, \mathrm{~m} \\
3.70, \mathrm{~m}\end{array}$ & 61.1, $\mathrm{CH}_{2}$ & $\begin{array}{l}3.88, \mathrm{~m} \\
3.71, \mathrm{~m}\end{array}$ \\
\hline
\end{tabular}

${ }^{a}$ Signals not distinguishable.

bacillaenes resist outside pathogens or competitors. When the production of bacillaenes increased to poison the host strain, detoxication mechanisms of intracellular glycosylation together with extracellular photo/oxidative degradation might be inspired. More interestingly, bacillaenes are "pseudo poisons" for the host cells that can be recovered after compound degradation. Conclusively, the antibiotic and biofilm enhancement of bacillaenes are two sides of a coin, both of which serve in the self-protection of Bacillus.

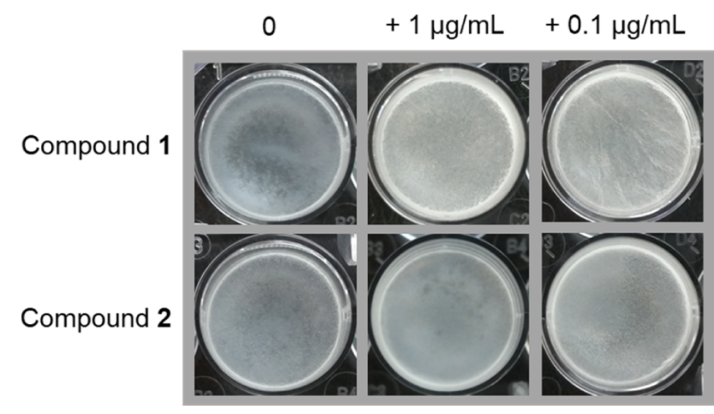

Figure 2. Microtiter plate assay of biofilm formation in the $B$ methylotrophicus B-9987 strain by addition of compounds 1 and 2 at concentrations of $0,0.1$, and $1 \mu \mathrm{g} / \mathrm{mL}$, respectively. The B-9987 strain was grown in MSgg medium at $37^{\circ} \mathrm{C}$ for $18 \mathrm{~h}$.

\section{EXPERIMENTAL SECTION}

3.1. General Experimental Procedures. $1 \mathrm{D}$ and $2 \mathrm{D}$ (DQF-COSY, HSQC, HMBC, and NOESY) NMR spectra were recorded on Bruker AVANCE III 600 spectrometers at $274 \mathrm{~K}$. Chemical shifts were reported with reference to the respective solvent peaks and the residual solvent peaks $\left(\delta_{\mathrm{H}}\right.$ 3.31 and $\delta_{\mathrm{C}} 49.0$ for $\left.\mathrm{CD}_{3} \mathrm{OD}\right)$. The NMR spectra were processed using the MestReNova 6.1.1 program. The Agilent series 1290 HPLC system equipped with Agilent 6430 triple quadrupole mass spectrometry was used for the quantitative LC-MS analysis. Analytical HPLC was performed on an Agilent 1260 Infinity apparatus with a diode array detector. Preparative HPLC was performed on a Hitachi Chromaster System.

3.2. Bacterial Strains and Culture Conditions. The wild-type and $\Delta b m m B$ mutant strains of B. methylotrophicus B9987 (CGMCC no. 2095) (Figure S22) have been described previously. ${ }^{12,16,17}$ Bacillus sp. B-5746 (Figure S22) was provided by Prof. Jianhua Ju (South China Sea Institute of Oceanology, Chinese Academy of Sciences). Bacillus strains were cultured in Luria-Bertani (LB) or Landy medium at 37 ${ }^{\circ} \mathrm{C}, 200 \mathrm{rpm}$. When appropriate, chloramphenicol (Chl; $5 \mathrm{mg} /$ $\mathrm{mL}$ for Bacillus) and erythromycin (Erm; $5 \mathrm{mg} / \mathrm{mL}$ for Bacillus) were added to the medium.

3.3. Preparation of Fr. BAEs and Fr. GBAEs. The $\triangle b m m B$ strain was cultivated in Landy medium at $37{ }^{\circ} \mathrm{C}(220$ $\mathrm{rpm}$ ) for $12 \mathrm{~h}$. The combined culture broth (9 L) was extracted with EtOAc and concentrated by a vacuum evaporator. The EtOAc extract was partitioned between equal volumes of $90 \% \mathrm{MeOH}$ and $n$-hexane to remove the nonpolar components. Then, the $\mathrm{MeOH}$ layer was concentrated and subjected to a stepped-gradient open column chromatography (ODS-A, $120 \AA$, S-30/50 mesh), eluting with $30,35,40,45$, and $50 \%$ ACN to yield five fractions. Then, each fraction was subjected to HPLC analysis with a linear gradient from 20 to $70 \% \mathrm{ACN} / \mathrm{H}_{2} \mathrm{O}$ in $60 \mathrm{~min}$ (YMC-Triart $\mathrm{C} 18$ column $150 \times 4.6 \mathrm{~mm}$, i.d. $5 \mu \mathrm{m}$; wavelength: $345 \mathrm{~nm}$; flow rate: $1 \mathrm{~mL} / \mathrm{min}$ ). The gBAEs and nonglycosylated bacillaenes were separated completely by this fractionation protocol, which were concentrated in $40 \%-\mathrm{ACN}$ and $45 \%-\mathrm{ACN}$ fractions, respectively. The entire experimental process was strictly conducted in the dark.

3.4. Isolation of the Compounds. Isolation of the pure bacillaenes was conducted as described in our previous work. ${ }^{9}$ Fr. BAEs were subjected to preparative HPLC (YMC-Pack ODS-A column $250 \times 20 \mathrm{~mm}$ ) eluting with $72 \% \mathrm{MeOH}$ (flow rate: $4 \mathrm{~mL} / \mathrm{min}$ ) at $345 \mathrm{~nm}$ to afford bacillaene $\mathrm{A}(\mathbf{1})$, and Fr. 
gBAEs afforded bacillaene B (2) and 14',15'-dihydrobacillaene $B$ (3). As the pure compounds 1-3 were very easily degraded during the vacuum evaporation process, each compound eluent was concentrated in batches $(<2 \mathrm{~mL} /$ flask $)$ to prepare PS. The DTS of compounds $\mathbf{2}$ and $\mathbf{3}$ were prepared by vacuum evaporation of each compound eluent for $20 \mathrm{~mL} /$ flask at one time. The entire experimental process was conducted in the dark.

3.5. Standard Curves for Compound Quantification. Different volumes $(10,30,50,70$, and $90 \mu \mathrm{L}$ for compound $\mathbf{1}$; 5, 10, 20, 40, and $80 \mu \mathrm{L}$ for compounds 2 and 3 ) of compound eluents obtained by the above HPLC purification method were injected to analytical HPLC (YMC-Pack ODS-AQ column 250 $\times 20 \mathrm{~mm}$ ) with a linear gradient from 30 to $70 \% \mathrm{~B} / \mathrm{A}$ in 30 min (phase B: $100 \% \mathrm{MeOH}$; phase $\mathrm{A}: \mathrm{H}_{2} \mathrm{O}$; flow rate: $1 \mathrm{~mL} /$ $\mathrm{min}$ ) at the wavelength of $345 \mathrm{~nm}$. The peak area of each injected compound eluent in the HPLC profiles was measured. Then, a portion of each compound eluent was evaporated completely and weighed to get the accurate concentration. The standard curves of pure compounds were established by comparing peak areas with the concentrations of the compounds.

3.6. Time- and Dose-Dependent Stability Tests. Compounds 1 and 2 were prepared into 10, 1, and $0.1 \mu \mathrm{g} /$ $\mathrm{mL}$ of aqueous solutions using the corresponding standard curve, respectively, and incubated at $37{ }^{\circ} \mathrm{C}$ for multitimepoints $(0,18,36$, and $48 \mathrm{~h})$ in the dark. The Agilent series 1290 HPLC system equipped with Agilent 6430 triple quadrupole mass spectrometry was used for the quantitative LC-MS analysis. The separations were carried out on a reversed-phase Thermos Hypersil GOLD C18 column $(100 \times$ $2.1 \mathrm{~mm}, 1.9 \mu \mathrm{m}, 175 \AA$, Thermo Scientific Inc., USA) with a linear gradient from 65 to $100 \% \mathrm{~B} / \mathrm{A}$ in $9 \mathrm{~min}$ for compound 2 and $15 \mathrm{~min}$ for compound $\mathbf{1}$ (phase B: $100 \% \mathrm{MeOH}$; phase A: $\mathrm{H}_{2} \mathrm{O}$; wavelength $345 \mathrm{~nm}$; flow rate: $0.2 \mathrm{~mL} / \mathrm{min}$ ). Fr. BAEs were prepared into 100,10 , and $1 \mu \mathrm{g} / \mathrm{mL}$ of aqueous solutions and incubated at $37^{\circ} \mathrm{C}$ in the dark for multi-timepoints $(0,18$, $24,36,48$, and $60 \mathrm{~h}$ ). HPLC analysis was performed on an Agilent $1260 \mathrm{HPLC}$ system with a linear gradient from 35 to $100 \% \mathrm{~B} / \mathrm{A}$ in $20 \mathrm{~min}$ (phase B: $100 \% \mathrm{MeOH}$; phase $\mathrm{A}: \mathrm{H}_{2} \mathrm{O}$; YMC-Pack ODS-A column $150 \times 4.6 \mathrm{~mm}$, i.d. $5 \mu \mathrm{m}$; wavelength: $345 \mathrm{~nm}$; flow rate: $1 \mathrm{~mL} / \mathrm{min}$ ). The programs Thermo Xcalibur 2.2 and Agilent ChemStation for LC 3D systems Rev. B. 04.03 were used for data analysis.

3.7. Biofilm Assay. A seed culture of the B- 9987 or B-5746 strain was grown in $\mathrm{LB}$ medium to an optical density $\left(\mathrm{OD}_{600}\right)$ of 1.0 at $600 \mathrm{~nm}$. Then, the seed solution was diluted to 1:1000 with sterile deionized water, and $15 \mu \mathrm{L}$ of the diluted culture and $1.5 \mu \mathrm{L}$ of the different concentrations of the test compounds were added to $1.5 \mathrm{~mL}$ of MSgg medium contained in a well of a 24 -well microtiter dish. The culture dish was incubated at $37^{\circ} \mathrm{C}$ for the specified time.

\section{ASSOCIATED CONTENT}

\section{SI Supporting Information}

The Supporting Information is available free of charge at https://pubs.acs.org/doi/10.1021/acsomega.0c03389.

HRESIMS data of compound 2; NMR spectroscopic data of compound 2, DTS-2, and DTS-3; results of stability tests and the biofilm assay; and NMR chemical shift data of compound 2 (PDF)

\section{AUTHOR INFORMATION}

\section{Corresponding Author}

Wenli Li - Key Laboratory of Marine Drugs, Ministry of Education, School of Medicine and Pharmacy, Ocean University of China, Qingdao 266003, China; Laboratory for Marine Drugs and Bioproducts of Qingdao National Laboratory for Marine Science and Technology, Qingdao 266237, China; (1) orcid.org/0000-0003-1598-3217; Email: liwenli@ouc.edu.cn

\section{Authors}

Huayue Li - Key Laboratory of Marine Drugs, Ministry of Education, School of Medicine and Pharmacy, Ocean University of China, Qingdao 266003, China; Laboratory for Marine Drugs and Bioproducts of Qingdao National Laboratory for Marine Science and Technology, Qingdao 266237, China; o orcid.org/0000-0002-9186-1804

Xiao Han - Key Laboratory of Marine Drugs, Ministry of Education, School of Medicine and Pharmacy, Ocean University of China, Qingdao 266003, China

Yujing Dong - Key Laboratory of Marine Drugs, Ministry of Education, School of Medicine and Pharmacy, Ocean University of China, Qingdao 266003, China

Shanshan Xu - Key Laboratory of Marine Drugs, Ministry of Education, School of Medicine and Pharmacy, Ocean University of China, Qingdao 266003, China

Chao Chen - Shandong Provincial Key Laboratory of Energy Genetics, Qingdao Institute of Bioenergy and Bioprocess Technology, Key Laboratory of Biofuels, Qingdao Institute of Bioenergy and Bioprocess Technology, and Qingdao Engineering Laboratory of Single Cell Oil, Qingdao Institute of Bioenergy and Bioprocess Technology, Chinese Academy of Sciences, Qingdao 266101, China

Yingang Feng - Shandong Provincial Key Laboratory of Energy Genetics, Qingdao Institute of Bioenergy and Bioprocess Technology, Key Laboratory of Biofuels, Qingdao Institute of Bioenergy and Bioprocess Technology, and Qingdao Engineering Laboratory of Single Cell Oil, Qingdao Institute of Bioenergy and Bioprocess Technology, Chinese Academy of Sciences, Qingdao 266101, China; (1) orcid.org/ 0000-0002-0879-1316

Qiu Cui - Shandong Provincial Key Laboratory of Energy Genetics, Qingdao Institute of Bioenergy and Bioprocess Technology, Key Laboratory of Biofuels, Qingdao Institute of Bioenergy and Bioprocess Technology, and Qingdao Engineering Laboratory of Single Cell Oil, Qingdao Institute of Bioenergy and Bioprocess Technology, Chinese Academy of Sciences, Qingdao 266101, China

Complete contact information is available at:

https://pubs.acs.org/10.1021/acsomega.0c03389

\section{Notes}

The authors declare no competing financial interest.

\section{ACKNOWLEDGMENTS}

This research was supported by the National Natural Science Foundation of China (NSFC) under grants 82073720, U1706206, 81991525, and 31570032, the National Key R\&D Program of China (2019YFC0312501), and the Foundation of Guangdong Key Laboratory of Marine Materia Medica (LMM2020-3). 


\section{REFERENCES}

(1) Patel, P. S.; Huang, S.; Fisher, S.; Pirnik, D.; Aklonis, C.; Dean, L.; Meyers, E.; Fernandes, P.; Mayerl, F. Bacillaene, a novel inhibitor of procaryotic protein synthesis produced by Bacillus subtilis: production, taxonomy, isolation, physico-chemical characterization and biological activity. J. Antibiot. 1995, 48, 997-1003.

(2) Butcher, R. A.; Schroeder, F. C.; Fischbach, M. A.; Straight, P. D.; Kolter, R.; Walsh, C. T.; Clardy, J. The identification of bacillaene, the product of the PksX megacomplex in Bacillus subtilis. Proc. Natl. Acad. Sci. U.S.A. 2007, 104, 1506-1509.

(3) Moldenhauer, J.; Chen, X.-H.; Borriss, R.; Piel, J. Biosynthesis of the antibiotic bacillaene, the product of a giant polyketide synthase complex of the trans-AT family. Angew. Chem. 2007, 46, 8195-8197.

(4) Reddick, J. J.; Antolak, S. A.; Raner, G. M. PksS from Bacillus subtilis is a cytochrome $\mathrm{P} 450$ involved in bacillaene metabolism. Biochem. Biophys. Res. Commun. 2007, 358, 363-367.

(5) Müller, S.; Strack, S. N.; Hoefler, B. C.; Straight, P. D.; Kearns, D. B.; Kirby, J. R. Predation by Myxococcus xanthus induces Bacillus subtilis to form spore-filled megastructures. Appl. Environ. Microbiol. 2014, 80, 5603-5610.

(6) Um, S.; Fraimout, A.; Sapountzis, P.; Oh, D. C.; Poulsen, M. The fungus-growing termite Macrotermes natalensis harbors bacillaeneproducing Bacillus sp. that inhibit potentially antagonistic fungi. Sci. Rep. 2013, 3, 3250.

(7) Nastro, R. A.; Arguelles-Arias, A.; Ongena, M.; Di Costanzo, A.; Trifuoggi, M.; Guida, M.; Fickers, P. Antimicrobial activity of Bacillus amyloliquefaciens ANT1 toward pathogenic bacteria and mold: effects on biofilm formation. Probiotics Antimicrob. 2013, 5, 252-258.

(8) Stein, T. Bacillus subtilis antibiotics: structures, syntheses and specific functions. Mol. Microbiol. 2005, 56, 845-857.

(9) Ongena, M.; Jacques, P. Bacillus lipopeptides: versatile weapons for plant disease biocontrol. Trends Microbiol. 2008, 16, 115-125.

(10) Sumi, C. D.; Yang, B. W.; Yeo, I.-C.; Hahm, Y. T. Antimicrobial peptides of the genus Bacillus: a new era for antibiotics. Can. J. Microbiol. 2015, 61, 93-103.

(11) Ye, M.; Tang, X.; Yang, R.; Zhang, H.; Li, F.; Tao, F.; Li, F.; Wang, Z. Characteristics and application of a novel species of Bacillus: Bacillus velezensis. ACS Chem. Biol. 2018, 13, 500-505.

(12) Li, H.; Han, X.; Zhang, J.; Dong, Y.; Xu, S.; Bao, Y.; Chen, C.; Feng, Y.; Cui, Q.; Li, W. An effective strategy for identification of highly unstable bacillaenes. J. Nat. Prod. 2019, 82, 3340-3346.

(13) Moldenhauer, J.; Götz, D. C. G.; Albert, C. R.; Bischof, S. K.; Schneider, K.; Süssmuth, R. D.; Engeser, M.; Gross, H.; Bringmann, G.; Piel, J. The final steps of bacillaene biosynthesis in Bacillus amyloliquefaciens FZB42: direct evidence for $\beta, \gamma$ dehydration by a trans-acyltransferase polyketide synthase. Angew. Chem. 2010, 49, $1465-1467$.

(14) Romero, D.; Traxler, M. F.; López, D.; Kolter, R. Antibiotics as signal molecules. Chem. Rev. 2011, 111, 5492-5505.

(15) Nonejuie, P.; Trial, R. M.; Newton, G. L.; Lamsa, A.; Ranmali Perera, V.; Aguilar, J.; Liu, W.-T.; Dorrestein, P. C.; Pogliano, J.; Pogliano, K. Application of bacterial cytological profiling to crude natural product extracts reveals the antibacterial arsenal of Bacillus subtilis. J. Antibiot. 2016, 69, 353-361.

(16) Liu, Y.; Zheng, H.; Zhan, G.; Qin, W.; Tian, L.; Li, W. Establishment of an efficient transformation protocol and its application in marine-derived Bacillus strain. Sci. China Life Sci. 2014, 57, 627-635.

(17) Qin, W.; Liu, Y.; Ren, P.; Zhang, J.; Li, H.; Tian, L.; Li, W. Uncovering a glycosyltransferase provides insights into the glycosylation step during macrolactin and bacillaene biosynthesis. Chembiochem 2014, 15, 2747-2753. 